\title{
THE EFFICIENCY EVALUATION OF MUTUAL FUND MANAGERS BASED ON DARA, CARA, IARA
}

\section{Mohammad Reza Tavakoli Baghdadabad ${ }^{1}$, Farid Habibi Tanha², Noreha Halid ${ }^{3}$}

\author{
Graduate School of Business, University Kebangsaan Malaysia, JALAN REKO, Universiti \\ Kebangsaan Malaysia, Bangi, Selangor, Malaysia \\ E-mails: ${ }^{1}$ Mr_tavakkoli@yahoo.com (corresponding author); ${ }^{2}$ farid_ht@yahoo.com; \\ 3noreha@ukm.my
}

Received 10 August 2011; accepted 17 December 2011

\begin{abstract}
We evaluate the efficiency of mutual fund managers of 20 different classes of management styles to identify the most efficient strategies and to propose an optimal pattern in selecting the funds by investors. We collect monthly data of 17,686 US mutual funds for a five-year period 2005-2010 to minimize the impact of survivorship bias and use Data Envelopment Analysis (DEA) model to evaluate the mutual fund performance. The set of considered inputs comprised "variance", representing the mutual fund risk, and "turnover, expense ratio and loads indicators", reflecting the mutual fund costs and fees. Two kinds of outputs are taken into account by our DEA model, "portfolio return" and "stochastic dominance indicators". As a unique contribution, we state the benefits of the DEA approach in the DARA, CARA, and IARA framework, and evaluate the efficiency of mutual funds based on fund strategies as well as the performance of best mutual funds among their group.

The evidence shows that the efficiency scores of technical, management, and scale are respectively $0.81,0.921$, and 0.874 for the DARA model, while the efficiency scores of two models of CARA and IARA are negligible. Also, we rank each management strategy in any model based on two methods - the number of referencing and the weighted value so that the managers of inefficient strategies must pattern the managers' ability of reference (efficient) strategies to improve their efficiency on the fund market in future.
\end{abstract}

Keywords: mutual fund, data envelopment analysis, stochastic dominance, DARA, CARA, IARA.

Reference to this paper should be made as follows: Tavakoli Baghdadabad, M. R.; Tanha, F. H.; Halid, N. 2013. The efficiency evaluation of mutual fund managers based on DARA, CARA, IARA, Journal of Business Economics and Management 14(4): 677-695.

JEL Classification: C14, C67, D53, D61.

\section{Introduction}

Mutual fund performance can be evaluated by either the parametric approach or nonparametric approach. The first approach has been frequently studied in the literature, 
while the second approach has been poorly considered in the performance evaluation models until now.

Earlier studies of fund performance evaluation are started with the models based on Jensen's alpha (i.e., Jensen 1968), and are then extended by adding more variables as explanatory factors (i.e., Carhart 1997) to improve the models. Most models are grounded on parametric models, in which they require a strong theoretical model and a benchmark to compute the outcome. Moreover, they only evaluate the funds performance in terms of the relationship between risk premium and return, without realizing the amount of resources that has been spent.

Data envelopment analysis is a non-parametric method used to evaluate the relative efficiency of decision-making units (DMU), which is first introduced by Charnes et al. (1978). DEA is employed for relative efficiency appraisal of DMUs. The efficiency evaluation of mutual fund managers in the DEA framework provides several advantages. First, unlike the parametric models, there is no necessity to run a theoretical model. Second, since the model evaluates the relative performance of funds, there is no need to assign a benchmark as well. Third, DEA does not require the assumptions of function forms relating inputs to outputs. Finally, DEA can incorporate factors needed into the model. Banker and Maindiratta (1986) explain that integral outcome of the DEA analysis is a set of inefficiency measure that identifies the source of the inefficiency and indicates the extent to which the various inputs need to be reduced or outputs need to be increased for making the inefficient DMUs efficient. The marginal share of each input or output can be clarified by this information.

Since research on the efficiency of mutual funds is scarce and only a few studies focus on this field (i.e., Murthi et al. 1997), we fill several gaps in the literature. First, we evaluate the full universe of more than 17,000 mutual funds in the Bloomberg database over the period 2005 to 2010 . This large sample provides the possibility of overcoming the small-sample problems that plagued prior studies concerning the efficiency evaluation of mutual fund. Second, unlike earlier studies, we evaluate funds managers' efficiency in terms of management style. Third, we propose an optimal choice pattern to make decisions in selecting the funds by investors; in addition, we prioritize efficient managers in terms of their own efficiency scores. Fourth, unlike earlier studies that only evaluate the funds in terms of relative (technical) efficiency, we calculate two other efficiency measures, namely, management and scale efficiency. Fifth, we propose three models of DEA in the Decreasing Absolute Risk Aversion (DARA), Constant Absolute Risk Aversion (CARA), and Increasing Absolute Risk Aversion (IARA) framework to identify the best model in evaluating the efficiency of fund managers.

\section{Background}

\subsection{Fund performance measurement}

Fund managers use many techniques to know how funds would perform. The performance measures enable managers to distinguish funds in terms of their performance. Although there are some performance measures, none of them can accurately predict 
the fund performance. The existing methods are simplistic and based on two variables, return and risk. They often disregard the amount of resource consumption for increasing one unit of return. Due to the fact that researchers are trying to propose a top model for the comprehensive evaluation of the performance of funds, they have extended the models in the framework of two parametric (i.e., Carhart 1997) and non-parametric approaches.

\subsection{Non-parametric approach}

Non-parametric approaches try to assess the efficacy of DMUs with multiple input and output. DEA is one of the non-parametric methods that can be used to evaluate a relative efficiency of DMUs (Charnes et al. 1978). It enables one to evaluate the relative efficiency of units as well as being able to overcome certain shortcomings of parametric approaches for performance evaluation. However, while several authors have studied the efficiency of funds, they have entirely excluded the evaluation of funds in terms of management and scale efficiency. The first study that uses the DEA methodology in measuring fund performances is related to Murthi et al. (1997). They evaluate the relative efficiency of funds, and then compare them with other parametric performance measures.

Basso and Funari (2001) consider two cost components and two risk components as DEA inputs. They evaluate the performance of 48 funds in three separate groups with the input-oriented DEA model supposing the constant return to scale and analyze them with and without a stochastic dominance index. Wilkens and Zhu (2001) propose characteristics of the returns' distribution as output. Along with returns, they add skewness and minimum return to more accurately assess fund performance. Similarly, Joro and $\mathrm{Na}$ (2002) extend this line of research and add distribution's third moment as output in their DEA model. The third order approximation based on a Taylor's series' expansion of a generalized utility function around the mean of the portfolio returns exhibits three desirable properties for utility functions, as proposed by Arrow and Pratt, namely, (i) positive marginal utility for wealth, (ii) decreasing marginal utility for wealth, and (iii) non-increasing absolute risk aversion.

Basso and Funari (2003) also use the multi-criteria capability of DEA to measure the ethical mutual funds' performance. They consider the ethical component, subscription, redemption fees and risk as DEA inputs, and also the expected return of funds as output. Lozano and Gutierrez (2008) find that most evaluation models overestimate risk, as in conventional models (such as DEA) the risk of mutual funds is calculated as a linear combination of fund assets. In other words, the effect of diversification is neglected. Thus, they propose a new DEA model combined with second-order stochastic dominance to compute the relative efficiency of mutual funds. The main advantage of this method is to consider the effects of portfolio diversification, which is neglected by the conventional DEA approaches.

However, the literature does not consider (i) an enough number of funds to minimize survivorship bias, (ii) management style as surveying class, (iii) management and scale efficiency scores as evaluation measures, and (iv) other stochastic dominance measures in the DEA model. 


\section{Methodology and data}

The DEA measures the relative performance of DMUs and the score of relative efficiencies with multiple outputs and inputs as:

$$
\text { Efficiency }=\frac{\text { Weighted Sum of Outputs }}{\text { Weighted Sum of Inputs }} .
$$

This is a linear programming model (LPM) that was developed by Charnes et al. (1978). They first proposed an input-oriented model with respect to constant returns to scale (CRS), and then extended the model based on a variable returns to scale (VRS) model.

\subsection{The constant return to scale (CRS)}

To describe the CRS model, assume that there is a set of $n$ DMUs and each unit defines $s$ output and $m$ input. The relative performance score of each unit is defined as

$$
\begin{gathered}
\text { Max } \quad h_{0}=\frac{\sum_{r=1}^{s} U_{r} Y_{r j}}{\sum_{i=1}^{m} V_{i} X_{i j}}, \\
\text { Subject to } \frac{\sum_{r=1}^{s} U_{r} Y_{r j}}{\sum_{i=1}^{m} V_{i} X_{i j}} \leq 1 \quad \forall i, \\
u_{r}, V_{i}>0 ; \quad \forall k, j,
\end{gathered}
$$

where $r=1$ to $s, i=1$ to $m, j=1$ to $n, Y_{r j}=$ amount of output $r$ produced by $\mathrm{DMU}_{i}$, $X_{i j}=$ amount of input $j$ used by $\mathrm{DMU}_{i}, U_{r}=$ weight given to output $r, V_{i}=$ weight given to input $i$. Since it is a nonlinear model, we change it to a linear model with assumption of $\sum_{i=1}^{m} V_{i} X_{i j}=1$ :

$$
\begin{aligned}
& \text { Max } h_{0}=\sum_{r=1}^{s} U_{r} Y_{r j}, \\
& \text { Subject to } \sum_{i=1}^{m} V_{i} X_{i j}=1, \\
& \sum_{r=1}^{s} U_{r} Y_{r j}-\sum_{i=1}^{m} V_{i} X_{i j} \leq 0 \quad \forall i, \\
& u_{r}, V_{i} \geq 0 ; \forall r, i .
\end{aligned}
$$

This model is run $n$ times (the number of DMUs) to compute the scores of relative performance of each DMU. This score is derived from the input and output weights of each DMU. Those DMUs getting a score of 1 are efficient and the others getting a score of less than 1 are inefficient. 


\subsection{The variable return to scale (VRS)}

The CRS assumption is only appropriate when all management styles are operating at an optimal scale. Many factors may cause a style to not operate at the optimal scale. Banker et al. (1984) propose a CRS DEA model to compute the VRS. The using of the CRS specification when not all styles are operating at the optimal scale will lead to technical (relative) efficiency, which is confounded by scale efficiency. Thus, the CRS can be easily justified to compute VRS by adding $N I^{\prime} \lambda=1$ to Eq. (4):

$$
\begin{gathered}
\operatorname{Min} \theta \\
S T-\sum_{r=1}^{s} u_{r} Y_{r j}+\sum_{r=1}^{s} \lambda_{j} Y_{i j} \geq 0, \\
\theta \sum_{i=1}^{m} v_{i} X_{i j}-\sum_{i=1}^{m} \lambda_{j} X_{i j} \geq 0, \\
\lambda \geq 0 \quad N I^{\prime} \lambda=1,
\end{gathered}
$$

where $N I^{\prime}$ is an $\mathrm{N} \times 1$ vector of one. The calculated technical efficiency by the VRS model is divided into management and scale efficiency.

To compute the scale efficiency, many studies decompose the technical efficiency scores obtained from a CRS DEA into two components - scale inefficiency and pure technical inefficiency. This may occur by computing both a CRS and a VRS on the same data. If there is a difference in the two technical efficiency scores for a given DMU, this shows that the DMU has scale inefficiency, and that the scale inefficiency can be computed by the difference between the VRS and CRS technical scores. One shortage of scale efficiency measure is that the value does not detect whether the DMU is operating in an area of the increasing or decreasing returns to scale. This may be determined by running an additional DEA problem with non-increasing return to scale (NIRS) imposed. This can be done by altering the DEA model in Eq. (4) by substituting the $N I^{\prime} \lambda=1$ restriction with $N I^{\prime} \lambda \leq 1$, as

$$
\begin{gathered}
\operatorname{Min} \theta \\
S . T-\sum_{r=1}^{s} u_{r} Y_{r j}+\sum_{r=1}^{s} \lambda_{j} Y_{i j} \geq 0, \\
\theta \sum_{i=1}^{m} v_{i} X_{i j}-\sum_{i=1}^{m} \lambda_{j} X_{i j} \geq 0, \\
N I^{\prime} \lambda \leq 1 \quad \lambda \geq 0 .
\end{gathered}
$$

\subsection{Prioritization of efficient DMUs}

Since it is possible to have more than one efficient style, the DEA ranks the efficient and reference styles in terms of the number of references and the weighted method as 


$$
\begin{aligned}
& \operatorname{Max}_{k} \\
& S . T:-D_{k} Y_{11}+\left(Y_{11} \lambda_{1}+Y_{21} \lambda_{2}+\ldots\right) \geq 0, \\
& \vdots \\
& -D_{k} Y_{1 j}+\left(Y_{1 j} \lambda_{1}+Y_{2 j} \lambda_{2}+\ldots\right) \geq 0 \\
& X_{11}-\left(X_{11} \lambda_{1}+X_{21} \lambda_{2}+\ldots\right) \geq 0 \\
& \vdots \\
& X_{1 i}-\left(X_{1 i} \lambda_{1}+X_{2 i} \lambda_{2}+\ldots\right) \geq 0
\end{aligned}
$$

where $D_{k}$ is inverse efficiency of $k^{\text {th }}$ DMU, $\lambda_{t}$ is decision variable, $Y_{1 j}$ is $j^{\text {th }}$ output for first DMU, and $X_{1 i}$ is $i^{t h}$ input for the first DMU (style).

It is clear that if the $k^{\text {th }}$ value of $\lambda_{j}$ equals zero, calculating the efficiency of $k^{\text {th }}$ DMU means that the $j^{\text {th }}$ DMU is not a reference for that DMU. The positive values show that the DMU is efficient. Moreover, the sum of the values of $\lambda_{j}$ after solving LPM is captured as DMU weight, which can be used for ranking.

\subsection{Data}

This study goes through the effect of different kinds of management styles on mutual funds performance. The 20 styles are considered based on the classification of the Bloomberg Database. Hence, the monthly data of 17,686 US mutual funds for a fiveyear period, 2005-2010, through the Database are collected to minimize the impact of survivorship bias.

\section{Research inputs and outputs}

Each DMU refers to a given management style category of mutual funds. We tend to evaluate the managers' efficiency of these categories. Hence, we use several criteria, comprising one measure of return and one measure of stochastic dominance in three different forms for the outputs $Y_{i j}$ to be taken into account. As well as both the costs and risk criteria of mutual funds for the outputs $X_{i j}$ to be considered. Due to the fact that inputs represent management activity instead of costly raw materials and because the ultimate purpose of the study is outputs produced by that activity, we use the outputoriented approach for two approaches of CRS and VRS.

Since the role of inputs and outputs are critical in the DEA, they are introduced as follows:

\subsection{Inputs}

Murthi et al. (1997) use the fund costs and fees, including subscription fees, redemption fees, operational expenses, purchase and sale costs and management fees, as one of the DEA inputs. They state that all costs are integrated in the expense ratio, loads 
and turnover indicators. Similarly, Daraio and Simar (2006) find that costs and fees are made by expense ratio, loads and turnover ratio, so they consider these costs as inputs. In this research these three indicators are used as our model inputs to reflect the role of fund costs and fees in the mutual fund performance.

Expense Ratio - the interactions between the performance of mutual funds and fund costs and fees report in many studies. Addressing the expense issue, the early work of Elton et al. (1993) and Carhart (1997) find a high relationship between fund performance and expenses. They explain that funds with high expense ratios have under performed. Mutual funds have a good financial status benefit from the increased size of their funds not by raising their costs and fees.

Turnover - the study of Friend and Blume (1970), in this thread show that a positive relationship between fund turnover and fund performance exists. The study of Daraio and Simar (2006) also shows that turnover gives an indication of trading activity: funds with higher turnover incur greater brokerage fees for affecting the trades.

Load Cost - Ippolito (1989) presents that load funds generally earn sufficiently higher rates of return compared with no-load funds to pay for the extra charges. Sirri and Tufano (1998) also find a relationship between fund performance and load cost.

Beta Coefficient - the second kind of input indicator for our DEA model is the Beta index. Although researchers are not unanimous in employing a similar risk measure, all believe that the risk parameter is one of the most important variables affecting the performance of funds. There are many techniques to quantify risk employed in different performance measures. However, most methods use standard deviation and beta. Murthi et al. (1997) employ the standard deviation as the measure of risk. Basso and Funari (2001) capture standard deviation and Beta as DEA inputs. They justify the selection of two risk measures and explain that the standard deviation of the returns is a proper risk measure for the investors who only hold one risky asset, and the Beta coefficient is for the investors who diversify their investments. Chang (2004) also applies standard deviation and beta coefficient as inputs. Thus, we use Beta coefficient as a risk measure because it quantifies a fund's volatility relative to the market as well as the beta measure commonly used for portfolio performance.

\subsection{Outputs}

Return - the most fundamental factor for mutual fund appraisal in both the parametric and non-parametric methods is the return on mutual fund, since all investors require a maximum return with minimum risk. To measure the return of portfolio and assets, some methods employ mean return, while others use excess return. Basso and Funari (2001) and Chang (2004) apply the mean return and Murthi et al. (1997) use the excess return as the output. Excess return is also used by Chen and Lin (2006), and Hsu and Lin (2007) as the output of the DEA model. This paper applies the mean return as one of the DEA model outputs as the mean return leads to a decrease in the presence of negative values.

DARA, CARA, and IARA - so far, some papers use a stochastic dominance indicator as output of the DEA model. Two concepts of the time occurrence of the returns and 
the investors' preference structure are reflected by the stochastic dominance index. This index is analyzed by giving a higher rank to the funds not dominated by other funds.

To apply stochastic dominance, although there is no need for any assumptions regarding the functional shape of the return distribution, it employs any function that is able to characterize a cumulative probability distribution. These stochastic dominance characteristics are consistent with the features of nonparametric methods, especially the DEA model. Basso and Funari (2001) are the first researchers who use a stochastic dominance indicator as one of the outputs of DEA model. They clearly state that a highly desirable property for a mutual fund is that it is not dominated by other funds - only the non-dominated portfolios can be considered efficient - which can easily happen in an analysis of fund returns over a long period. A fund turns out to be dominated in some years but not in others. Hence, a stochastic dominance indicator can be defined by determining in how many periods of a fund is efficient according to a given stochastic dominance criterion. Basso and Funari (2003) use the DARA as output, and Chen and Lin (2006) and Lozano and Gutierrez (2008) apply the DARA index in the DEA model.

Thus, we propose a stochastic dominance criterion to each fund corresponding to investors' preferences (manager') and investors' attitude (managers') towards risk. There are three kinds of attitude towards risk:

- Risk averse: If an investor is presented with two kinds of investments, and he prefers the investment with the lower risk, then he is called risk averse $\left(U^{\prime \prime}(0)<0\right)$.

- Risk Neutral: If an investor is only concerned with an investment's return and overlooks risk, then he is called risk neutral $\left(U^{\prime \prime}(0)=0\right)$.

- Risk Seeking: if an investor prefers to take big risks to raise the potential return on investments, then he is called risk seeking $\left(U^{\prime \prime}(0)>0\right)$.

$U$ " is the second derivative of the utility function of wealth. The utility functions are models that describe an investor's attitude toward risk. Fig. 1 shows the relationship between investor' wealth and utility from three different aspects.

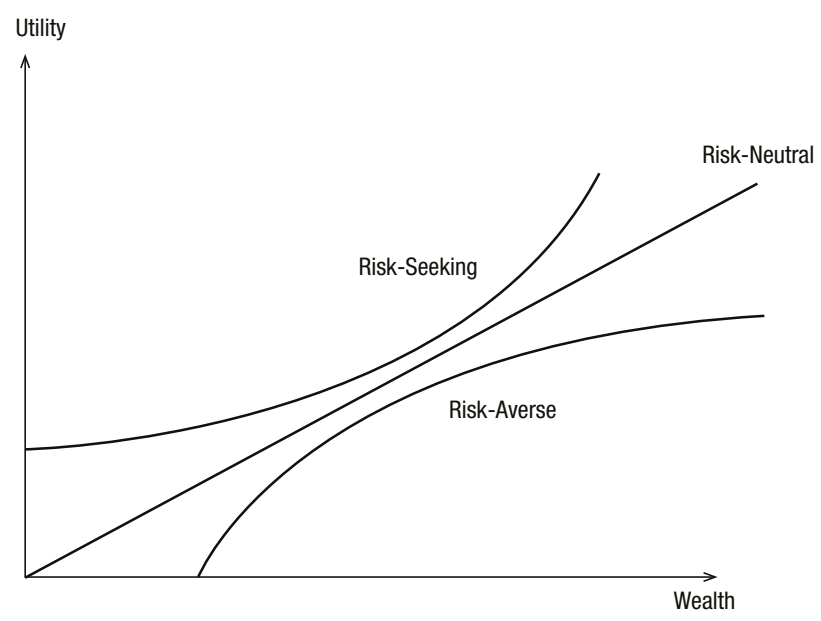

Fig. 1. The utility function of investors 
It is the second derivative of the utility function of wealth. The utility function is able to describe the effect of fluctuations in wealth on investor's preferences. An investor exhibits three kinds of absolute risk aversion as follows:

- DARA: If investor's demand for investing in risky assets increases as his wealth rises.

- CARA: If investor's demand for investing in risky assets keeps the same as his wealth changes.

- IARA: If investor's demand for investing in risky assets decreases as his wealth rises.

Arrow (1971) and Pratt (1964) design a coefficient of absolute risk aversion to show how investors behave. This coefficient of absolute risk aversion is defined as:

$$
A(w)=-\frac{u^{\prime \prime}(w)}{u^{\prime}(w)} .
$$

The first derivative of $A(w)$ at wealth is an index of how absolute risk aversion behaves with changes in wealth. Now, absolute risk aversion can be calculated with respect to $A^{\prime}(w)$ as:

- Increasing absolute risk aversion $A^{\prime}(w)>0$;

- Constant absolute risk aversion $A^{\prime}(w)=0$;

- Decreasing absolute risk aversion $A^{\prime}(w)<0$.

The functions of absolute risk aversion are unique. Thus, the first and second derivatives of utility functions at wealth can be easily computed. In the next stage, the coefficients of absolute risk aversion with Arrow and Pratt's measure are obtained. Finally, by the first derivative of the absolute risk aversion coefficient, three measures of DARA, CARA and IARA are computed and presented in Table 1.

Table 1. The relation of DARA, CARA and IARA

\begin{tabular}{llllll}
\hline $\begin{array}{l}\text { Absolute } \\
\text { Risk Aversion }\end{array}$ & $U(w)$ & $U^{\prime}(w)$ & $U^{\prime \prime}(w)$ & $A(c)=-\frac{U^{\prime}(w)}{U^{\prime \prime}(w)}$ & $A^{\prime}(w)$ \\
\hline DARA & $\log (w)$ & $\frac{1}{c \ln (10)}$ & $-\frac{1}{c^{2} \ln (10)}$ & $\frac{1}{w}$ & $-\frac{1}{w}$ \\
\hline CARA & $1-e^{-\alpha w}$ & $\alpha e^{-\alpha w}$ & $-\alpha^{2} e^{-\alpha w}$ & $\alpha$ & 0 \\
\hline IARA & $c-\alpha w^{2}$ & $1-2 \alpha w$ & $-2 \alpha$ & $\frac{2 \alpha}{1-2 \alpha w}$ & $\frac{2 \alpha}{(1-2 \alpha w)^{2}}$ \\
\hline
\end{tabular}

We use Net Asset Value (NAV) of mutual funds instead of the wealth (w) variable. There are three different Stochastic Dominance measures used. Thus, the DEA is run three times, and each time one of the measures of absolute risk aversion is considered as the output of our DEA model. 


\section{Empirical evidence}

We test the DEA model for different classes of fund strategies discussed in the prior sections on all data available for the US market. We consider the annual returns of 17,555 funds. These funds belong to a variety of fund strategies as reported in Table 2. The DEA evaluates the managers' efficiency of each class. We use the mean return along with three dominance relations of CARA, DARA, and IARA as the output of funds, besides the four inputs - fund turnover, expense ratio, load cost, and variance. Then 17 distinguished LPMs are run to compute the efficiency scores of technical, management, and scale based on the inputs and outputs. In order to compare the fund strategies performance with the behavior of a market benchmark, we use three measures - Sharpe, Treynor, and Jensen's alpha - to investigate the correlation between each of the three efficiencies with the market benchmark indexes.

Table 2 reports the descriptive statistics for the 17 categories of US funds strategies. It shows an average of net asset value for each fund strategy in the range of 1 to 27.72 billion dollars. The second column shows the five-year average of fund turnover, which represents substantial trading activity in fund strategies. The next column represents the 5 -year mean and standard deviation of any strategy for the two measures of Sharpe and Treynor, respectively. The last column also shows the number of funds in each of the fund strategies.

Table 2. The descriptive statistics of funds strategy

\begin{tabular}{lccccccc}
\hline & & & \multicolumn{2}{c}{ Sharp Index } & \multicolumn{2}{c}{ Treynor Index } & \\
\cline { 3 - 7 } Fund Strategy & NAV & Turnover & Mean & $\begin{array}{c}\text { Standard } \\
\text { Deviation }\end{array}$ & Mean & $\begin{array}{c}\text { Standard } \\
\text { Deviation }\end{array}$ & N \\
\hline Blend & 18.05 & 89.9 & 0.13 & 0.12 & 0.05 & 0.05 & 1312 \\
\hline Contrarian & 12.57 & 367.4 & -0.41 & 0.26 & 0.08 & 0.09 & 82 \\
\hline Current Income & 10.2 & 86.81 & 0.43 & 0.42 & 0.16 & 0.73 & 3454 \\
\hline Emerging Market & 20.72 & 77.17 & 0.39 & 0.09 & 0.17 & 0.05 & 396 \\
\hline Equity Income & 15.05 & 56.39 & 0.16 & 0.14 & 0.10 & 0.6 & 294 \\
\hline First Tier & 1.03 & 1.29 & -8.58 & 99.2 & 57.8 & 83.9 & 534 \\
\hline Geographically Focused & 17.54 & 74.29 & 0.13 & 0.16 & 0.07 & 0.38 & 2304 \\
\hline Government \& Agency & 1 & 0.08 & -7.33 & 47.9 & 6.76 & 5.42 & 332 \\
\hline Growth & 20.3 & 97.15 & 0.17 & 0.12 & 0.07 & 0.14 & 2457 \\
\hline Growth \& Income & 21.97 & 55.5 & 0.1 & 0.11 & 0.04 & 0.02 & 195 \\
\hline Index Fund & 27.72 & 127.7 & 0.12 & 0.13 & 0.05 & 0.05 & 630 \\
\hline Long-Short & 12.72 & 259.8 & -0.1 & 0.21 & -0.08 & 0.17 & 129 \\
\hline Market Neutral & 12.01 & 326.4 & -0.17 & 0.48 & -3.05 & 3.39 & 83 \\
\hline Principal Preservation & 14.6 & 18.31 & 1.31 & 3.49 & -1.12 & 1.97 & 21 \\
\hline Sector Fund & 21.39 & 114.8 & 0.19 & 0.2 & 0.1 & 0.09 & 1320 \\
\hline Total Return & 11.15 & 196 & 0.68 & 0.4 & 0.12 & 0.21 & 1805 \\
\hline Value & 17.83 & 62.71 & 0.12 & 0.13 & 0.06 & 0.14 & 2207 \\
\hline & & & & & & & \\
\hline & & & & & & & \\
\hline
\end{tabular}


Then we use the CRS model assuming constant returns to scale for computing technical efficiency, and the VRS model assuming variable returns to scale to compute management and scale efficiency. Considering the two models, first the DEA model is computed in the DARA form with the two outputs of DARA and return and four input variables of fund turnover, expense ratio, load cost, and variance. Table 3 shows the results of the DARA model, in which six fund strategies - Contrarian, First Tier, Government \& Agency, Growth \& Income, Index Fund, and Principal Preservation - have the highest technical, management, and scale efficiency scores compared to the others. The average value of the three efficiencies is $0.81,0.921$, and 0.874 , which means that assuming all other conditions are fixed, the three efficiencies of relative, management, and scale have empty capacity equal to $0.19,0.079$, and 0.126 , respectively.

One of the most important objectives of the DEA model is to determine the reference fund strategies for inefficient strategies. Thus, we identify the reference strategies based on the results of software Deap2, as shown in Table 4.

Table 4 represents the reference strategies for each fund separately (i.e., three strategies for Contrarian, Growth \& Income, and Index Fund, which, respectively, are a reference strategy for Blend). These interpretations can be followed for other fund strategies, meaning that each fund strategy manager must consider the performance of its own preference strategies as a pattern to achieve a level of efficiency in future. As shown in Table 4, the efficient strategies (i.e., Contrarian and Government \& Agency) are selfreferenced.

Table 3. The results of different efficiencies with DARA

\begin{tabular}{lcccc}
\hline Fund Strategy & $\begin{array}{c}\text { Technical } \\
\text { Efficiency }\end{array}$ & $\begin{array}{c}\text { Management } \\
\text { Efficiency }\end{array}$ & $\begin{array}{c}\text { Scale } \\
\text { Efficiency }\end{array}$ & Scale Type \\
\hline Blend & 0.83 & 0.91 & 0.91 & Drs \\
\hline Contrarian & 1 & 1 & 1 & - \\
\hline Current Income & 0.84 & 0.84 & 0.99 & Irs \\
\hline Emerging Market & 0.73 & 0.98 & 0.74 & Drs \\
\hline Equity Income & 0.78 & 0.88 & 0.89 & Drs \\
\hline First Tier & 1 & 1 & 1 & - \\
\hline Geographically Focused & 0.70 & 0.91 & 0.77 & Drs \\
\hline Government \& Agency & 1 & 1 & 1 & - \\
\hline Growth & 0.77 & 0.93 & 0.82 & Drs \\
\hline Growth \& Income & 1 & 1 & 1 & - \\
\hline Index Fund & 1 & 1 & 1 & - \\
\hline Long-Short & 0.46 & 0.81 & 0.57 & Drs \\
\hline Market Neutral & 0.44 & 0.79 & 0.55 & Drs \\
\hline Principal Preservation & 1 & 1 & 1 & Drs \\
\hline Sector Fund & 0.67 & 0.93 & 0.72 & Drs \\
\hline Total Return & 0.73 & 0.73 & 0.99 & Drs \\
\hline Value & 0.79 & 0.92 & 0.85 & \\
\hline Mean & 0.81 & 0.92 & 0.87 & \\
\hline
\end{tabular}


Table 4. The results of determining the preference strategies

\begin{tabular}{|c|c|c|c|c|}
\hline Fund Strategy & Strategy 1 & Strategy 2 & Strategy 3 & Strategy 4 \\
\hline Blend & Contrarian & $\begin{array}{c}\text { Growth \& } \\
\text { Income }\end{array}$ & Index Fund & - \\
\hline Contrarian & Contrarian & - & - & - \\
\hline Current Income & Contrarian & First Tier & $\begin{array}{l}\text { Growth \& } \\
\text { Income }\end{array}$ & Index Fund \\
\hline Emerging Market & Contrarian & $\begin{array}{c}\text { Growth \& } \\
\text { Income }\end{array}$ & Index Fund & - \\
\hline Equity Income & $\begin{array}{l}\text { Growth \& } \\
\text { Income }\end{array}$ & Index Fund & - & - \\
\hline First Tier & First Tier & - & - & - \\
\hline Geographically Focused & Index Fund & $\begin{array}{c}\text { Growth \& } \\
\text { Income }\end{array}$ & - & - \\
\hline Government \& Agency & $\begin{array}{c}\text { Government } \\
\& \text { Agency }\end{array}$ & - & - & - \\
\hline Growth & $\begin{array}{l}\text { Growth \& } \\
\text { Income }\end{array}$ & Index Fund & - & - \\
\hline Growth \& Income & $\begin{array}{l}\text { Growth \& } \\
\text { Income }\end{array}$ & - & - & - \\
\hline Index Fund & Index Fund & - & - & - \\
\hline Long-Short & Index Fund & Contrarian & - & - \\
\hline Market Neutral & Contrarian & Index Fund & - & - \\
\hline Principal Preservation & $\begin{array}{c}\text { Principal } \\
\text { Preservation }\end{array}$ & - & - & - \\
\hline Sector Fund & Index Fund & $\begin{array}{c}\text { Growth \& } \\
\text { Income }\end{array}$ & - & - \\
\hline Total Return & Index Fund & Contrarian & - & - \\
\hline Value & Index Fund & $\begin{array}{l}\text { Growth \& } \\
\text { Income }\end{array}$ & - & - \\
\hline
\end{tabular}

Since the six strategies in our study are determined as reference, the DEA model is able to rank each reference strategy. Using two methods - "number of referencing" and "weighted number of references" - we rank each reference strategy. To rank the strategies based on the first method, the number of referencing is computed for each efficient strategy after running the 17 LPMs. A strategy will become a reference unit, if its efficiency score has the highest frequency. To rank the strategies based on the second method, the weighted average is calculated for each efficient strategy and their ranking is done according to the weighted average of each efficient unit when they are preferred (Table 5).

Then, the two methods of CRS and VRS are again used to compute the DEA model in the CARA form while considering two outputs of CARA and return and four input variables of fund turnover, expense ratio, load cost, and variance. Table 6 shows that three strategies of Contrarian, First Tier, and Government \& Agency have the highest technical, management, and scale efficiency scores compared to the others. The average values of the three efficiencies are $0.463,1$, and 0.463 , respectively, which means 
Table 5. The ranking of funds strategy

\begin{tabular}{lcccccc}
\hline Fund Strategy & $\begin{array}{c}\text { Index } \\
\text { Fund }\end{array}$ & $\begin{array}{c}\text { Growth \& } \\
\text { Income }\end{array}$ & Contrarian & $\begin{array}{c}\text { First } \\
\text { Tier }\end{array}$ & $\begin{array}{c}\text { Government \& } \\
\text { Agency }\end{array}$ & $\begin{array}{c}\text { Principal } \\
\text { Preservation }\end{array}$ \\
\hline $\begin{array}{l}\text { Number of } \\
\text { Referencing }\end{array}$ & 12 & 9 & 7 & 2 & 1 & 1 \\
\hline $\begin{array}{l}\text { Weighted Number } \\
\text { of References }\end{array}$ & 7.06 & 6.13 & 1.58 & 1.12 & 1 & 1 \\
\hline
\end{tabular}

that assuming all other conditions being fixed, the two efficiencies of relative and scale, similarly, have considerable empty capacity equal to 0.537 .

To determine the preference strategies, the evidence of Table 6 shows that the six strategies are referred to each other. Moreover, the ranking of preference of strategies based on the method of the number of referencing shows that three fund strategies - Principal Preservation, Contrarian, and Current Income - have the highest rankings, while the ranking of the method of the weighted number of references detects that three strategies - Principal Preservation, Current Income, and Contrarian - have the highest rankings, respectively.

Similarly, the DEA model is computed in the IARA form while considering the two outputs of IARA and return and four research input variables. Table 7 shows the results of the model IARA, where similar to the CARA model, three fund strategies - Contrarian, First Tier, and Government \& Agency - have the highest technical, management, and scale efficiency scores compared to the others. The average values of the three efficiencies are $0.286,0.611$, and 0.383 , respectively, which means that assuming all other conditions being fixed, three efficiencies have considerable empty capacity equal to $0.714,0.389$, and 0.617 , which is worse than the CARA model.

To determine the preference strategies, Table 6 shows that ten strategies are referenced for the surveying strategies. Moreover, the ranking of preference strategies based on the method of the number of referencing and the weighted number of references shows that three strategies - Government \& Agency, Contrarian, and First Tier - are respectively ranked among the surveying strategies.

In order to compare the fund strategies performance with the behavior of a market benchmark (Table 8), we make the correlation between three measures of Sharpe, Treynor, and Jensen's alpha with each of the three efficiencies computed by the DEA involving technical, management, and scale efficiency. Table 9 represents the correlation coefficients between three DEA models - CARA, DARA, and IARA - with three conventional measures - Sharpe, Treynor, and Jensen's alpha. The evidence shows that the average correlation coefficient of the DARA for technical efficiency is 0.54 , while the average of this coefficient for the CARA and IARA models is 0.61 and 0.57 , respectively. For management efficiency, the average of the correlation coefficients for DARA, CARA, and IARA are 0.48, 0.62, and 0.56, respectively. Similarly the results of the correlation coefficients of IARA are almost similar to DARA, in which the three models of DARA, CARA, and IARA have values equal to $0.52,0.61$, and 0.56 , respectively. Moreover, the values of the Sharpe, Treynor, and Jensen's alpha measures have been normalized by dividing the values by the highest value. 


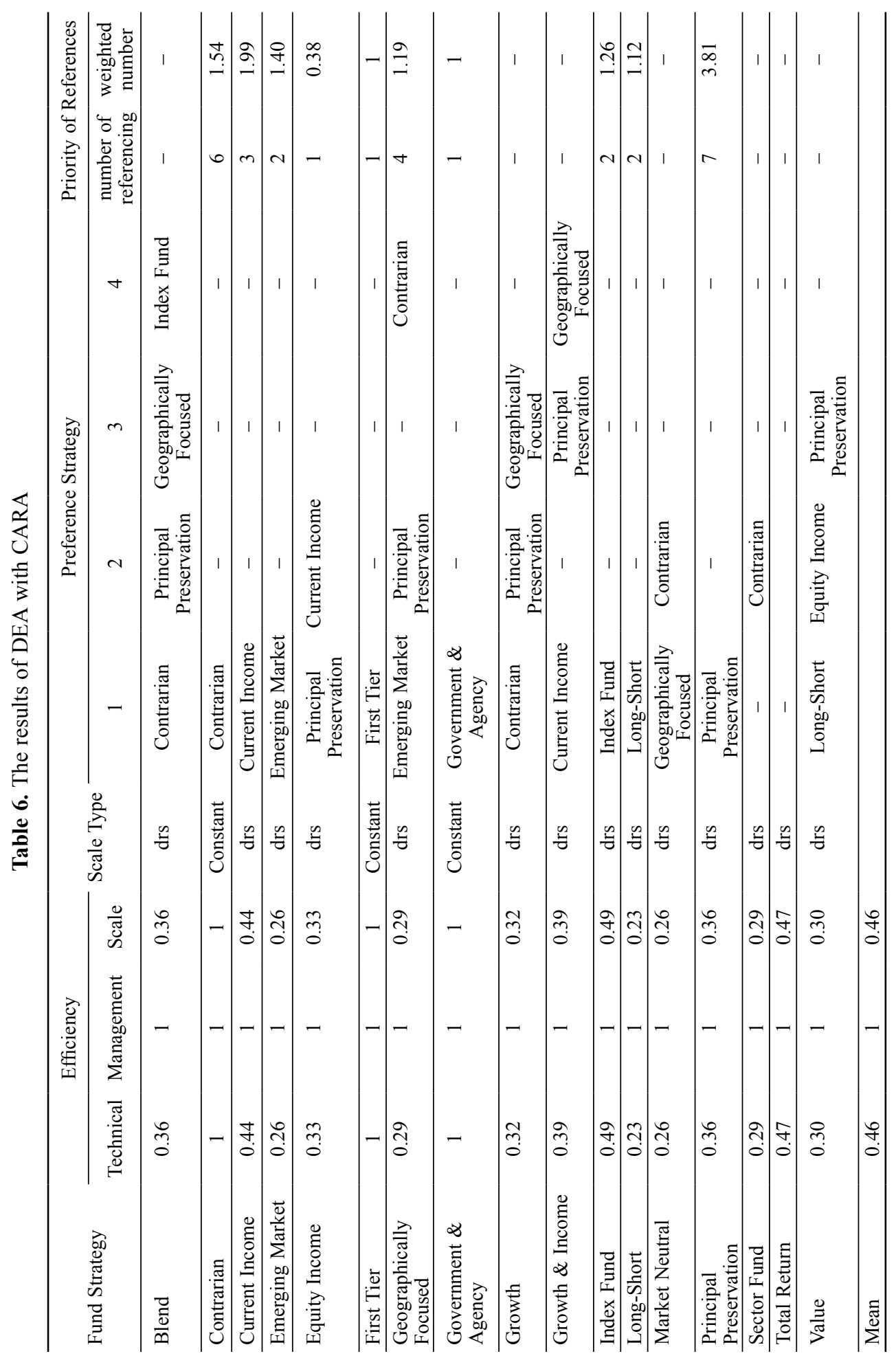




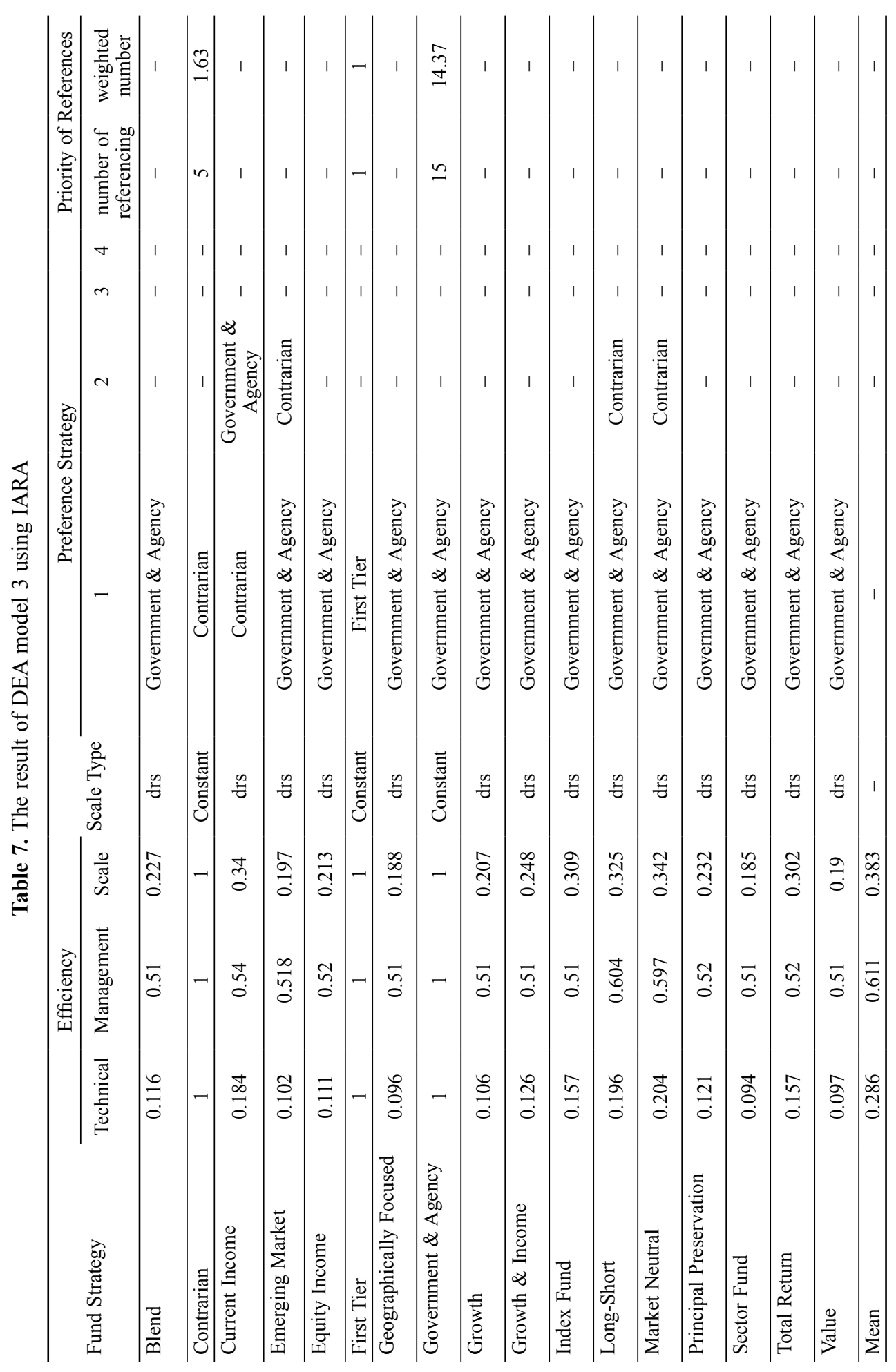


Table 8. Conventional measures versus DARA, CARA, and IARA

\begin{tabular}{lcccccc}
\hline \multirow{2}{*}{ Fund Strategy } & \multicolumn{3}{l}{ Measures } & \multicolumn{3}{c}{ Technical Efficiency } \\
\cline { 2 - 7 } & Sharpe & Treynor & Jensen's Alpha & DARA & CARA & IARA \\
\hline Blend & 0.09 & 0.001 & -0.18 & 0.82 & 0.36 & 0.11 \\
\hline Contrarian & -0.31 & 0.001 & -3.50 & 1 & 1 & 1 \\
\hline Current Income & 0.32 & 0.003 & 0.19 & 0.8 & 0.44 & 0.18 \\
\hline Emerging Market & 0.30 & 0.003 & -0.50 & 0.73 & 0.26 & 0.10 \\
\hline Equity Income & 0.12 & 0.002 & 0.63 & 0.78 & 0.33 & 0.11 \\
\hline First Tier & -6.51 & 1 & 0.03 & 1 & 1 & 1 \\
\hline Geographically Focused & 0.10 & 0.001 & 0.04 & 0.70 & 0.29 & 0.09 \\
\hline Government \& Agency & -5.55 & 0.117 & 0.28 & 1 & 1 & 1 \\
\hline Growth & 0.13 & 0.001 & -0.01 & 0.77 & 0.32 & 0.10 \\
\hline Growth \& Income & 0.08 & 0.001 & -0.12 & 1 & 0.39 & 0.12 \\
\hline Index Fund & 0.09 & 0.001 & -0.42 & 1 & 0.49 & 0.15 \\
\hline Long-Short & -0.07 & -0.001 & -1.62 & 0.46 & 0.23 & 0.19 \\
\hline Market Neutral & -0.13 & -0.053 & -1.08 & 0.44 & 0.26 & 0.20 \\
\hline Principal Preservation & 1 & -0.019 & -0.03 & 1 & 0.36 & 0.12 \\
\hline Sector Fund & 0.14 & 0.002 & 1 & 0.67 & 0.29 & 0.09 \\
\hline Total Return & 0.51 & 0.002 & 0.09 & 0.73 & 0.47 & 0.15 \\
\hline Value & 0.09 & 0.001 & 0.09 & 0.79 & 0.30 & 0.09 \\
\hline
\end{tabular}

\section{Conclusions}

We propose a replacement approach to evaluate the performance of mutual fund managers. We combine the DEA model and stochastic dominance criteria and propose two new measures in the form of CARA and IARA dominance relations along with the DARA model previously suggested by Basso and Funari (2001) to evaluate the technical, management, and scale efficiency of 17,555 US funds. The three DEA models being proposed in the form of CARA, DARA, and IARA are used to evaluate the managers' efficiency of management styles. Unlike prior studies that compute the technical efficiency on the funds, we extend the analysis on two other efficiencies, namely, management and scale. Moreover, we compute the efficiency scores and determine the preference strategy for each fund strategy.

The evidence shows that the scores of technical, management, and scale efficiency are respectively $0.81,0.921$, and 0.874 for the DARA, while the efficiency scores of the CARA and IARA are negligible. Moreover, each strategy in any model is ranked based on two methods - the number of referencing and the weighted number of references - so that the managers of inefficient strategy must pattern the managers' ability of reference (efficient) strategies to improve its efficiency on the fund market in future.

Finally, since the average correlation coefficient between the IARA model and the three measures - Sharpe, Treynor, and Jensen's alpha - is higher than the two other models, it is able to provide a better explanation of the DEA model than the others. 





As a proposition for future studies, the three DEA models in the DARA, CARA, and IARA form can be studied in terms of the cross DEA model to improve the results.

\section{References}

Arrow, K. J. 1971. Essays in the theory of risk-bearing. Chicago: Markham.

Banker, R. D.; Charnes, R. F.; Cooper, W. W. 1984. Some models for estimating technical and scale inefficiencies in Data Envelopment Analysis, Management Science 30(9): 1078-1092. http://dx.doi.org/10.1287/mnsc.30.9.1078

Banker, R. D.; Maindiratta, A. 1986. Piecewise loglinear estimation of efficient production surfaces, Management Science 32(1): 126-135. http://dx.doi.org/10.1287/mnsc.32.1.126

Basso, A.; Funari, S. 2001. A data envelopment analysis approach to measure the mutual fund performance, European Journal of Operational Research 135(3): 679-698.

http://dx.doi.org/10.1016/S0377-2217(00)00311-8

Basso, A.; Funari, S. 2003. Measuring the performance of ethical mutual funds: a DEA approach, The Journal of the Operational Research Society 54(5):521-531.

http://dx.doi.org/10.1057/palgrave.jors.2601541

Carhart, M. M. 1997. On persistence in mutual fund performance, Journal of Finance 52(1): 57-82. http://dx.doi.org/10.1111/j.1540-6261.1997.tb03808.x

Chang, K. P. 2004. Evaluating mutual fund performance: an application of minimum convex input requirement set approach, Computers \& Operations Research 31: 929-940.

http://dx.doi.org/10.1016/S0305-0548(03)00044-3

Charnes, A.; Cooper, W. W.; Rhodes, E. 1978. Measuring the efficiency of decision making units, European Journal of Operational Research 2(6): 429-444.

http://dx.doi.org/10.1016/0377-2217(78)90138-8

Chen, Z.; Lin, R. 2006. Mutual fund performance evaluation using data envelopment analysis with new risk measures, Or Spectrum 28(3): 375-398.

http://dx.doi.org/10.1007/s00291-005-0032-1

Daraio, C.; Simar, L. 2006. A robust nonparametric approach to evaluate and explain the performance of mutual funds, European Journal of Operational Research 175(1): 516-542.

http://dx.doi.org/10.1016/j.ejor.2005.06.010

Elton, E. J.; Gruber, M. J.; Das, S.; Hlavka, M. 1993, Efficiency with costly information: a reinterpretation of evidence from managed portfolios, Review of Financial Studies 6(1):1-22.

http://dx.doi.org/10.1093/rfs/6.1.1

Friend, I.; Blume, M. E. 1970. Measurement of portfolio performance under uncertainty, American Economic Review 60(4): 561-575.

Hsu, C.-S.; Lin, J.-R. 2007. Mutual fund performance and persistence in Taiwan: a non-parametric approach, The Service Industries Journal 27(5): 509-523.

http://dx.doi.org/10.1080/02642060701411658

Ippolito, R. 1989. Efficiency with costly information: a study of mutual fund performance, 19651984, Quarterly Journal of Economics 104(1): 1-23. http://dx.doi.org/10.2307/2937832

Jensen, C. M. 1968. The performance of mutual funds in the period 1945-1964, Journal of Finance 23(2): 389-416. http://dx.doi.org/10.1111/j.1540-6261.1968.tb00815.x

Joro, T.; Na, P. 2002. Data envelopment analysis in mutual fund evaluation. A critical review. University of Alberta School of Business management science, WP 02-2.

Lozano, S.; Gutirrez, E. 2008. Data envelopment analysis of mutual funds based on second-order stochastic dominance, European Journal of Operational Research 189: 230-244.

http://dx.doi.org/10.1016/j.ejor.2007.04.014 
Murthi, B. P. S.; Choi, Y. K.; Desai, P. 1997. Efficiency of mutual funds and portfolio performance measurement: a non-parametric approach, European Journal of Operational Research 98(2): 408-418. http://dx.doi.org/10.1016/S0377-2217(96)00356-6

Pratt, J. W. 1964. Risk aversion in the small and in the large, Econometrica 32(1/2): 122-136. http://dx.doi.org/10.2307/1913738

Sirri, E. R.; Tufano, P. 1998. Costly search and mutual fund flows, Journal of Finance 53(5): 1589-1622. http://dx.doi.org/10.1111/0022-1082.00066

Wilkens, J.; Zhu, K. 2001. Portfolio evaluation and benchmark selection: a mathematical programming approach, The Journal of Alternative Investments 4(1): 9-19.

http://dx.doi.org/10.3905/jai.2001.319003

Mohammad Reza TAVAKOLI BAGHDADABAD was born in Iran in 1976. His studies' background is in the field of Management and Finance.

Farid Habibi TANHA was born in Iran in 1983. He is DBA student of the Graduate School of Business, National University of Malaysia-UKM since 2010.

Noreha HALID was born in Malaysia in 1963. She is Associate Professor of Graduate School of Business, National University of Malaysia, UKM since 2009. 